\title{
«Some records are impossible to break with a natural body»... Et alors?
}

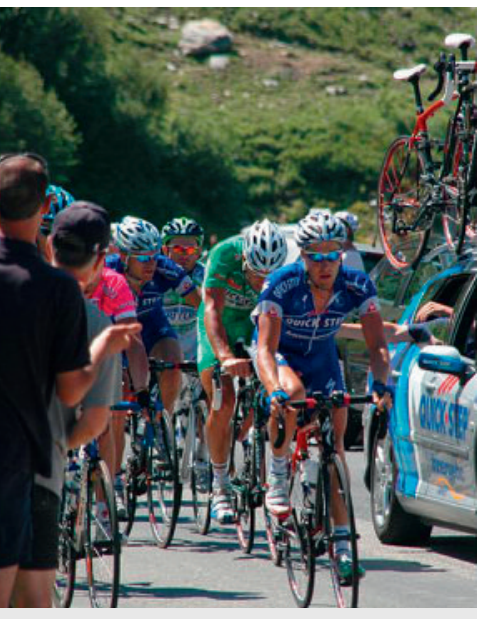

Performance maximale à tout prix? Quel prix, pour quoi?

1 Missa JN. Sport, enhancement and the inefficacy of antidoping policy. Bioethica Forum. 2011;4(1):14-6.

2 Kayser B, Mauron A, Miah A. Current anti-doping policy: a critical appraisal. BMC Medical Ethics. 2007;8:2.

3 Martin J. Dopage: rien de changé depuis Rome et «panem et circenses»? Bull Méd Suisses. 2006;87(41):1791-2

4 Martin J. Ethique sportive Dopage et genre: à propos de la recherche d'équité dans le sport. Bull Méd Suisses. 2010;91(23):920-1.
Dans la dernière livraison de Bioethica Forum, l'intéressant journal de la Société suisse d'éthique biomédicale, je suis interpellé par un article de Jean-Noël Missa, personnalité belge de la bioéthique [1]. D'abord par la phrase qui fait le titre du présent billet: serait-ce un but essentiel que les records sportifs soient toujours battus? Que perdrions-nous si, classiquement, les compétitions désignent les meilleurs du moment, sans qu'il soit obligatoire de comparer à ce qui valait à Olympie ou au $\mathrm{XX}^{\mathrm{e}}$ siècle? Evoquera-t-on la fatalité chez l'humain de vouloir toujours plus et plus vite? Mais au moment où Fukushima et d'autres le climat, une économie creusant toujours plus les inégalités au lieu de les combler - posent derechef des questions majeures sur nos manières de «progresser», l'urgence est d'atténuer dite fatalité, d'agir contre elle.

Missa juge discutable la pratique actuelle de la lutte contre le dopage. A noter dans son texte les expressions suivantes (traduit de l'anglais): «le dopage fait partie de l'essence du sport de compétition», «la technologie biomédicale (améliorative) est au cœur du sport d'élite», et «n'est-il pas paradoxal de vouloir interdire un comportement (usage de moyens artificiels) qui est au centre du sport de compétition?» Est-ce là vraiment la bonne manière de décrire la substance du sport?

On a le droit de se mettre en danger en faisant de l'escalade, de la course motorisée ou simplement en fumant. Alors que beaucoup d'athlètes prennent des produits prohibés, serait-il liberticide de vouloir protéger leur santé contre leur gré? Préoccupé d'éthique dans une visée communautaire et soucieuse des conséquences, je reste favorable à la lutte contre le dopage parce que les dégâts liés à sa pratique libre, «médicalement supervisée» mais larga manu, seraient plus graves. On peut dire il est vrai que, actuellement, dirigeants et athlètes sont poussés à "chercher mieux» dans la clandestinité, mais il est certain que la prise de produits potentiellement toxiques est - au niveau du collectif des athlètes - moins importante que ce que favoriserait une libéralisation.

Imaginer que le dopage libre sous supervision médicale serait moins pathogène est une illusion. Pour cela, il faut croire à la perfection de l'homme, des médecins et des dispositifs que l'homme met en place - je suis très surpris que des universitaires éminents y croient. Chers collègues, vous savez que tout système stimule la créativité en vue de le tourner ou de le porter à des conséquences ultimes inquié- tantes. Vous critiquez l'angélisme/irréalisme des tenants de l'anti-dopage, mais tombez dans ce même travers en pensant que tout sera «en ordre» si un spécialiste surveille l'athlète. Or, quand inévitablement des dizaines de sportifs auront été «tués» par les prescriptions médicales, on criera au scandale et on voudra des contrôles (des compétences des médecins notamment - il en existe de mauvais) et des limites (exclure les produits décidément trop dangereux à court ou long terme), etc. En quoi alors aura-t-on changé le paradigme actuel?

Il faut tenir compte du fait que le sport de compétition retient l'attention du grand public dans le monde entier et exerce ainsi une forte influence. Le sport a - aussi - un rôle d'exemplarité; les responsables du sport et ceux de la société en général l'affirment vigoureusement. Et je trouve pour le moins simplificateur de dire, en faveur de la liberté de (se) doper: «Ainsi, traduire les améliorations que permet le dopage en avantages gagnés - en ayant les meilleurs scientifiques dans son équipe - serait plus proche des valeurs de la compétition» (Missa, citant [2]).

S'agissant de politique de la drogue - concernant la population en général -, l'expérience m’a appris à refuser les doctrines punitives, «vertueuses», qui font beaucoup de mal à des individus fragiles tout en encensant l'abstinence comme unique issue valable. J'ai œuvré pour des pratiques aidant les toxicomanes, des «cassés» de la vie, à gérer au mieux leur situation, y compris à l'aide de stupéfiants (méthadone par ex.). Mais cette position ne mène pas à accepter le dopage libre en matière sportive. Le sport d'élite est un sousensemble particulier de la société et les professionnels du soin, liés à «Primum non nocere», ne sauraient avoir pour métier de charger de produits dangereux des jeunes gens a priori sains, avec le risque qu'ils deviennent eux aussi des «cassés» de la vie - y compris par des effets secondaires longtemps après.

Enfin, personne n'est obligé de s'adonner à la compétition s'il n'en aime pas les règles. Le débat sur le dopage est complexe mais le modèle «anything goes» (tout est permis) est décidément trop beau pour être vrai. La société serait bien avisée de garder à l'esprit l'adage selon quoi la liberté ne vaut que par les limites qu'on lui met $[3,4]$.

Jean Martin, membre de la rédaction et de la Commission nationale d'éthique 